\title{
FACEBOOK IN TEACHING: STRENGTHS AND WEAKNESSES
}

\section{INTRODUCTION}

Social networks are communities of people who share some type of interest. The Internet as well as Web 2.0 and 3.0 technologies do nothing but amplify our social networks. According to Gneiser, Heidemann, Klier, Landherr and Probst (2012), online social networks allow individuals to build a public or semi-public profile within a well-defined system, to articulate a list of users with whom they have a connection and, finally, to see and cross their connections list with others made by different individuals belonging to the system too. The use of social networks has grown at dizzying speed in recent years. Data supplied by the Nielsen consultancy (2011) reveal that 4 out of 5 active Internet users utilise them. In the case of Spain, $93 \%$ of the internet-user population owns active accounts on social networks, with an average of 2.31 networks per individual, a progressive sophistication being observed among users due to a consolidated track record, to the emergence of new proposals, and to the more frequent and intense access through new devices such as smartphones or tablets (The Cocktail Analysis, 2013; Suki, 2013).

The fact that they have been immersed, educated and raised around technology defines a new generation characterised by their trust in the mass media, their multitasking abilities with technologies and their proneness towards everything that is new. Young undergraduates have as some of their main features the importance that they assign to interaction and their consumption of large amounts of online information, and they are the most communicative generation to date. They are also used to self-directed, independent learning, being able to obtain information from different media (Mills, 2011). Learners are digital natives; they are not only accustomed to being connected with one another but also expect to be connected 
permanently, that is, $24 / 7$. In contrast, lecturers are digital immigrants, but we have the responsibility to convert a technology which is likely to become a distraction into a teaching tool that encourages problem-solving, facilitates the use of information sources, improves collaboration and makes possible interaction among students (Siegle, 2011).

Social networks consequently permit to publish and share information, self-leaming, teamwork, feedback, and contact with experts; in short, they are a perfect tool for constructivist and collaborative learning. However, despite the increased utilisation of social networks, only few students use them for their studies; that is why it would be interesting to analyse whether these networks can become a good complement to the formal training received in university classrooms. Social networks constitute an attractive tool in the academic field because the student is thoroughly familiar with them and is consequently willing to establish a more fluent communication for the purpose of carrying out an exchange of knowledge, information and ideas (Dogoriti, Pange and Anderson, 2014).

Among all social networks, Facebook is the most often used one (Nielsen, 2011; The Cocktail Analysis, 2013). Facebook is an example of Web 2.0 technology which has an enormous potential in the field of education, though it was not created to construct or handle learning experiences. It operates within an open platform, unlike other systems organised around formally structured courses. As a matter of fact, although Facebook is not a learning environment, it can act as very valuable support for the new social orientations which are currently appearing in educational processes. Facebook represents a great opportunity to generate knowledge and cohesion within groups (Llorens-Cerdà and Capdeferro-Planas, 2011).

These are the reasons why the present paper seeks to show our teaching experience with the Facebook social network in Human Resource Management degree subjects. This experience 
will help us highlight the strengths and weaknesses of Facebook in teaching-making an effort to assess them too. A brief literature review on the topic "networks, Facebook and teaching" will be performed to that end, conclusions and recommendations being drawn for a better use of social networks in the context of university teaching. Students' opinions, expressed through a survey, will help detect their degree of satisfaction with this new tool.

\section{LITERATURE REVIEW}

\subsection{Social networks and teaching}

Several social networks have been created ad hoc for teaching, amongst them Internet en el aula, Tioki or Schoolfy. Internet en el aula [Internet in the classroom] (https://internetaula.ning.com/) is a network created by the Instituto Nacional de Tecnologías Educativas y Formación del Profesorado [National Institute of Educational Technologies and Teacher Training] of the Spanish Ministerio de Educación, Cultura y Deporte [Ministry of Education, Culture and Sport]. It boasts blogs, multimedia to share photographs, videos, postcasts and events to keep the educational agenda up to date. As for Tioki (http://vww.linkedin.com/company/tioki), it has been defined as the LinkedIn for educators. It is a social network for professionals of education which permits to create an experience and resource exchange community. Finally, Schoolfy (http://www.schoolfy.com/es/) is an educational platform aimed at advanced teaching management with the idea that lecturers can create their own private social network that can help them manage the whole learning process. All three of them have in common that they are teacher-centred networks.

On the other hand, Moodle (platform created in 1999 for online teaching) is perceived by students as another formal learning tool. Hence the importance of using social networks, which are seen by young students as a way of achieving communication and friendship because, if the student uses a tool that he can handle easily and that he does not perceive as 
something compulsory, one can reach that student through a non-formal path. The utilisation of universal, generalist platforms turns out to be interesting in this respect.

For this reason, although some lecturers think that generalist social networks lack adequate and specific tools for the learning process and that they do not suffice for teaching, various experiences show satisfactory and clearly successful results within the framework of generalist social networks for teaching (Suwannatthachote and Tantrarungroj, 2012; Li and Pitts, 2009).

\subsection{Facebook as a teaching network}

For various reasons, and not only because it is the most popular one, Facebook stands out among virtual social networks. Unlike other social networks, which focus on some specific goal or interest that is common to their users, Facebook is centred on users themselves. In other words, this network is articulated around them, without a clear objective or another rule other than the dissemination of their own virtual existence. Users are the owners of their own space and also of their profile (Llorens-Cerdà and Capdeferro-Planas, 2011).

Facebook is a network closely linked to the everyday life of its users. The most popular activities are likes and comments, which on average take place 3.2 billion times a day, and 300 million photographs are posted on this network worldwide within a similar period of time, (Wang, 2013).

Facebook allows users to interact with people that they already knew outside the Internet or to meet new virtual friends. It additionally provides social and emotional support, information resources and ties with other individuals who live, work or study around them. Users can offer information about themselves in their online profiles, share resources with friends who can publish their comments on the pages of all their friends and see their profiles. Facebook users can join similar groups of people with the same interests, receive and update news and 
share information. Facebook provides a variety of functions, including games, virtual pets and farms, gifts, etc.

Nevertheless, Facebook may become a tool not only to relax -since social networks usually represent an activity associated with free time and low stress levels- but also to help students learn and educate themselves simultaneously. It can actually be used to perform the same type of functions that were already carried out by other ICTs, such as communicating students with one another, or with their teacher, receiving announcements or updates, and also managing projects and collaboration schemes outside the classroom. The good thing about Facebook is that many students have already become familiar with it and therefore feel at ease using it. Students can not only be more collaborative thanks to the utilisation of Facebook but also develop a greater motivation to learn (Mahmud and Ching, 2012). Bringing Facebook and teaching together makes it possible to break the four walls of a classroom and gives students a place where they can interact with one another in order to effectively improve their learning (Halawati and Soh, 2013).

\subsection{Strengths of Facebook in teaching}

Although Facebook has already been with us for a decade, many possibilities still remain to be explored about the network as a whole (Lamb and Johnson, 2013) and about the advantages that its use can bring in the teaching environment. These strengths can be summarised in four, namely: Communication; Participation; Motivation; and Performance.

a) Communication. The same as any other ICT tool, Facebook is a means to exchange information or, expressed differently, for communication. Facebook improves interaction, which turns out to be an essential element required both for the knowledge acquisition process and for cognitive and physical development (Wang, 2013). It permits formal as well as informal communication, which is needed around classroom activities. It can help students 
organise themselves within a subject, reducing the costs of communication with other students (Lampe et al., 2011). This informal character fits in with the uses and forms of social interaction that are common among students, who have adopted them as a channel to reach their friends and as a tool for collaborative work (Suwannathachote and Tantrarungroj, 2012). It permits both synchronous and asynchronous communication (Llorens-Cerdà and Capdeferro-Planas, 2011), removing time and place restrictions while simultaneously facilitating students' mobility (Omar, Embi and Yunus, 2012).

The democratisation of communication with this tool, between teachers and students, and between students themselves, fosters a community and social learning culture, where a quick feedback is expected (Wang, 2013).

b) Participation. Social networks encourage contributions by anybody who is interested in a topic, so that everyone can create, edit or share information. Participation is additionally made easier because it represents a good way to communicate between students who are bashful or shy, it helps them to lose their inhibitions, and they can participate more openly than face to face (Omar, Embi and Yunus, 2012). Just as there are shy and daring students, some students are more competent than others. Working together on social networks will probably help them learn from one another (Ramírez et al., 2009).

In contrast with unidirectional media, like the teacher-student relationship in a typical lecture, social networks are multidirectional; control is decentralised and open to the masses of users. This has led lecturers to become less and less the authorised knowledge sources and to behave increasingly as facilitators of exploration and collaboration, in search of questions, opportunities and solutions to problems (Duncan and Barczyk, 2013).

The above does not mean that all users are going to contribute in the same way and to the same extent in a network like Facebook; in the study by Duvall and Kirwin (2012), only 26\% 
of the students had participated by means of posts or comments on the course's web page; a majority of them (46\%) were passive observers, they made neither comments nor likes, and they did not upload any links or publications either. Therefore, due to the nature of Facebook, plenty of users may be watching other people's posts or comments without doing anything else, without commenting on them or sending "likes," etc. In this respect, Facebook makes possible both a many-to-many culture and a few-to-many culture where most interactions actually happen within a very small group of users (Cain and Policastri, 2011).

c) Motivation. From the academic point of view, the utilisation of Facebook at universities significantly improves the motivation to learn as well as the learning atmosphere in the classroom, and it improves the relationship between teachers and students too (Wang, 2013). For example, the objective sought through the introduction of Facebook in one subject in the study by Duvall and Kirwin (2012) was to encourage students to participate more often in the discussion of topics related to that subject outside the classrooms. These authors started from the hypothesis that integrating online interaction associated with the subject, with the social network most frequently used by students, might improve visibility as well as participation.

The truth is that Facebook can improve the group membership feeling, but it additionally strengthens the impression among students that they are actually learning (Duncan and Barczyk, 2013). The students who are in classes with cooperative learning groups show a greater motivation to reach goals and a stronger community feeling than those who do not form part of cooperative groups. Numerous studies on out-of-class interaction have proved that contact between teachers and students is positively correlated with personal, social and intellectual results and with the general degree of satisfaction of students with their learning experience (Li and Pitts, 2009). 
Authors such as Cain and Policastri (2011) additionally highlight the fact that subjects may be more motivating and interesting when they incorporate the direct testimony of experts in the field who are difficult to take to the classroom for monetary and/or logistic reasons. Facebook makes it possible to upload videos or posts made by these experts, thus improving the appeal of subjects.

d) Performance. Both lecturers and students have as our priority interest to improve students' performance as well as their academic outcomes. Although a number of studies have been written about the use of Facebook and its connection with learners' academic performance, no categorical results have been obtained, mainly because most of these studies did not focus on the use of Facebook for academic or learning purposes but simply analysed which students used Facebook and which ones did not, along with their academic performance -and very often those who were regular Facebook users devoted fewer hours to study. In other words, not many research works have so far dealt with the utilisation of Facebook as part of the curriculum or of the way to teach students (Wang, 2013), which is why this fourth strength may become the most controversial one.

It is undoubtedly worth highlighting the paper by Duvall and Kirwin (2012), though. These authors concluded that a more intense use of the Facebook web page associated with the subject had been made during exam weeks, which leads us to assume that students sought better preparation for their exams through Facebook contents.

However, it must be remembered that Facebook may have positive and negative influences on students' results. The time spent in playing and other entertainment applications may be inversely correlated to students' marks, but Facebook may be used to start projects, download videos, share ideas or simply strengthen friendship ties, comradeship and the group membership feeling, all of which will positively influence their academic results (Wang, 
2013). Facebook can act an instrument for mixing the social and academic lives of students. According to Fortune, Spielman and Pangelinan (2011), the use of Facebook by students has no impact on their academic performance; it does not worsen their marks and, in fact, most of the time devoted to the use of social networks will be to the benefit of working with classmates to prepare class assignments.

\subsection{Weakmesses of Facebook in teaching}

However, the literature review equally allows us to identify some weaknesses in the use of Facebook as a teaching tool which can be summarised in the following three aspects: Privacy; Technological Deficit; and Time.

a) Privacy. Sharing ideas or information on Facebook requires befriending our interlocutors on the Internet; nevertheless, some studies suggest that students are distrustful of teachers asking them to establish a friendly relationship on social networks such as Facebook (Taylor, Mulligan and Ishida, 2012). That is to say, students do not usually want to be friends of their lecturers on Facebook; they may look at their profile or send them a message, but only as an isolated activity -becoming friends implies a longer-term relationship (Lampe et al., 2011). This is why many lecturers decide to keep their personal Facebook apart from their professional one, as it may also happen to students. There are both studies according to which students want to keep Facebook apart from their academic world and others which reveal that students want to use Facebook for academic tasks because they are accustomed to using this network and because it is easy to use (Siegle, 2011). The study by Taylor, Mulligan and Ishida (2012) shows that learners do not support an indiscriminate use of their Facebook web page; they prefer to establish a separation between their private Facebook and the utilisation of social networks for academic purposes. They fear that their privacy can be compromised and they do not think that academic and personal or friendship matters should be mixed, 
especially with their current teachers -although they do not have so many misgivings with their past teachers. The main reason why students do not want to use social networks such as Facebook or Twitter for academic matters lies in their concerns about privacy as well as in the difficulty to draw the limits between their work as students and their private life.

b) Technological deficit. Lecturers tend to believe that students are experts in Facebook, but this is not always the case (Harris, 2012). A growing number of recent studies have started to demonstrate that many of the so-called digital natives are not so technologically fluent or skilful as it had been originally assumed, to such an extent that the notion of digital natives could be a myth and that many young people placed within that age group may not own the knowledge to be fluent in technological matters (Shaltry et al., 2013).

c) Time. Attention should also be paid to the work overload which can be generated as a result of using this network, since the use of Facebook sometimes does not replace that of other materials or other software (Duvall and Kirwin, 2012); in fact, it complements them, and the teacher must be aware of the fact that, although Facebook or other networks may be more or less friendly or entertaining, they still require dedicating time to them. Because Facebook is so easy to use, and since posts, videos and so on can be uploaded so fast, there is a risk for us to end up saturating the system with information, thus forcing students to learn how to handle such information overloads (Duncan and Barczyk, 2013). In this sense, it is worth highlighting that the comment system may make it difficult to see all the information, especially if the user is not familiar with its use, as comments overlap each other. Facebook does not have a system to organise information -by topics, for instance; just as quickly as new information appears, it may disappear buried by more new information, and it is impossible to classify it in such a way that it can be easily seen (Llorens-Cerdà and Capdeferro-Planas, 2011). 


\section{Page 11 of 23}

Moreover, next to relevant information, Facebook contains a whole lot of distractions which are real time thieves, amongst them, advertisements, warnings, suggestions, games, etc.

\section{METHODOLOGY}

We began to use Facebook as a teaching tool in official degree subjects during the 2013-14 academic year; more precisely, this network was used with students enrolled on Human Resource Management subjects from the degrees in Business and Human Resources (HR). A total of 191 students were asked to give us their opinion on the use of Facebook in teaching. The network inside Facebook which was created for this experience has 242 members, amongst whom are both students enrolled on the aforementioned subjects and lecturers teaching them, as well as experts in Human Resource Management who have kindly offered to enrich this experience with their contribution.

The possible alternatives with the Facebook network were explored prior to creating the work environment. A decision was made to set up a closed group in which personal issues and the information about the subject would mix as little as possible. Every participant in this network previously had to be accepted by its administrator.

It was also our conviction that this initiative should stem from the teaching staff, since they are the ones who played a hierarchical role as the network administrator who could censor or moderate the different comments or decide about the acceptance of a new network member. Both teachers and students have the chance to upload their information, comments, links, etc., thus creating a work environment characterised by being as democratic as possible.

The web page became operational on 28 January 2014, the functioning of the subjects linked to it having started exactly one day earlier. The lecturer in charge of the said subjects announced this event both on Facebook and in the actual classrooms. The use of this page is 
voluntary, and the information shared therein can prove useful to illustrate, exemplify or elaborate on the subject's contents, but students will not be directly tested on its knowledge. Seeking to assess students' views about our teaching experience on Facebook, a questionnaire was administered to them during our classes in which they were asked to mention both negative and positive aspects which could be associated with the use of Facebook in the classroom. 125 out of 191 enrolled students completed the questionnaire (which represents $65.4 \%$ of the total); since the sampling error is situated at $5.26 \%$, it can be considered that the answers obtained are representative of the total population analysed (see Table 1).

\section{TABLE 1}

With regard to the questionnaire, it contains 22 questions; the first one, for them to say if they are registered on the Facebook network which is being assessed; the following 8 questions, for them to give their opinion on possible negative aspects or weaknesses that Facebook may have as a teaching instrument; and the last 13 questions -which can only be answered by students registered on the aforesaid network- for them to indicate the positive aspects that they have found in it. The measures used for the constructs on weaknesses and strengths are explained in Table 2, and the questionnaire can be found in the ANNEX.

TABLE 2

\section{RESULTS}

Table 3 shows us that $35(61.4 \%)$ of the learners who answered the questionnaire were studying Business, whereas $90(67.1 \%)$ of them were enrolled on HR -no significant difference was obtained between the representation of both degrees. A significant difference does exist, though, between the degree on which students are enrolled and the fact of being registered or not on the Facebook web page. The chi-square statistic confirms a prevalence of Business students over those in HR as far as registration on the subject's Facebook is 
concerned; while the percentage of registered students reaches $94.3 \%$ among the former (only 2 of the interviewed students were not registered), the figure goes down to $65.6 \%$ among the latter (31 HR students were not registered).

\section{TABLE 3}

\subsection{Weaknesses}

All the learners who answered the questionnaire gave their views about the weaknesses of Facebook as a teaching tool, regardless of whether they had registered on the Facebook group of our subjects or not. To our mind, even those who are not registered can thus explain to us the reasons why they have not registered. The analysis about the items referring to weaknesses shows that the three most important ones for students are: not wanting to give access to their private information; followed by not wanting friendship with teachers through Facebook; and not wanting to use Facebook in the degree subjects -since its utilisation must be social, for fun. Among the least important weaknesses stand out not wanting to learn to use Facebook, not wanting to maintain a friendly relationship with classmates on Facebook or being unable to manage on Facebook.

TABLE 4

The analysis about differences of means between the items related to Facebook weaknesses for students registered on the subject's group and those who are not reveals that the students who are not registered are the ones who least want friendship with their classmates on Facebook and who least want to use it for the degree subjects; and neither do they want to learn to use this tool (Table 4). Furthermore, the examination of the significant differences of means according to the degree on which students are enrolled allows us to detect that HR students are the ones who least want to make friends with the teaching staff and use Facebook in subjects. 
The 8 initial items about weaknesses of Facebook in teaching provided us with the basis to calculate three variables: the first one of them, called PRIVACY, was calculated with the mean of the items corresponding to questions 2 to 5 ; in turn, the calculation of the second one, named TECHNOLOGICAL DEFICIT, was based on the mean of the items contained in questions 6 and 7; and finally, the third variable-TIME- was calculated with the mean of the items appearing in questions 7 to 9.

\section{FIGURE 1}

The next step consisted in calculating the mean of each variable created from Facebook weaknesses, and it can be observed in Figure 1 that, above all, students fear the loss of privacy that the use of Facebook as a teaching tool can mean to them; and, in second place, the extra time that they will most probably have to dedicate to using this tool; and also that much less consideration is given to their technological problems, associated with their inability to use -or their refusal to learn- this technology.

\section{TABLE 5}

Furthermore, using a difference of means test once again (Table 5) allows us to confirm the statistically significant difference between weaknesses related to privacy and technological deficit. In both cases, the learners who have not registered on the subject's Facebook and those studying HR are the ones who mostly refer to these weaknesses of Facebook as a teaching tool.

\subsection{Strengths}

As for the strengths that the interviewed students perceive in the use of Facebook for teaching, it must be said that these questions were only answered by the learners who had registered on the Facebook group of our subjects since, in our opinion, someone who has not 
used this tool cannot possibly express an opinion on the advantages that they have found in its utilisation.

The analysis about the items referring to strengths shows that the three most important ones identified by students are: being able to use the subject's Facebook in order to say "Like" to some publications or comments associated with it; being able to use it as a passive participant (taking a look at the information and nothing else); and being on the whole satisfied with the Facebook social network which has been created for the subject. The items corresponding to strengths which have received the lowest score were, in ascending order: using Facebook to upload subject contents; improving the relationship with classmates through the utilisation of Facebook; and, thirdly, being able to use the network to make comments about the subject. In short, it is perceived that, despite students' satisfaction, a rather passive use of the network prevails. No significant differences of means were found in terms of strengths among students depending on the degree they were enrolled on.

The 13 initial items about the strengths of our Facebook social network provided us with the basis to calculate four variables: the first one of them, called COMMUNICATION, was calculated with the mean of the items corresponding to questions 10 to 11 ; in turn, the calculation of the second one, named PARTICIPATION, was based on the mean of the items contained in questions 12 and 15 ; the third variable -MOTIVATION- was calculated with the mean of the items appearing in questions 16 to 19 ; and the last one, which was given the name of PERFORMANCE, stemmed from the content of questions 20 to 22 .

\section{FIGURE 2}

The next step consisted in calculating the mean of each variable created from Facebook strengths, and it can be observed in Figure 2 that, above all, students check that being registered on the Facebook network contributes to academic performance; followed very 
closely by the improved communication with other network members. A lower score is given to aspects such as participation on the network and the motivation that it can entail.

\section{CONCLUSIONS}

Facebook is not a passing trend; in fact, it is becoming something ubiquitous; it can be found everywhere; hence the need for us professionals of education to explore ways in which this social network can be used for educational purposes.

Weighing up the strengths and weaknesses of Facebook allowed us to reach the conclusion that an initial experience with it cannot mean its compulsory use in the subject, but a voluntary use. According to our understanding, a blended learning experience which combines in-class teaching with online teaching, and where Facebook is mostly present in the second part, constitutes the most appropriate choice. It is additionally worth remembering that some students may not be users of Facebook or other social networks for personal reasons or due to technological barriers, and this has to be taken into account when it comes to imposing such a tool as a compulsory part of teaching (Cain and Policastri, 2011).

Making the activity in Facebook optional was essential to verify the interest among students, as they were not forced to memorise the materials and they did not have to work with stress either. Thus, students read those articles in which they were interested -and not all of them simply because they were obliged to do so. Moreover, if a requirement had been fixed for all students to upload one post, for example, the truly interesting posts might have ended up lost or hidden among the mass of other uninteresting ones, which would have been uploaded to cause a good impression or to comply with some minimum requirements.

Most of the interviewed students (73\%) registered on the subject's Facebook web page, and they make a positive assessment about the use of social networks as a teaching-learning tool. Experience shows that using Facebook can positively impact on the performance of students, 
who are satisfied with the experience, think that the information obtained in Facebook can improve their training, and claim that it should be used in other subjects as well.

However, the Facebook users of our experience see themselves rather as passive users, insofar as they prefer to check what others do on Facebook instead of offering their own comments, videos or news. Students' interaction in the form of news or comments was small, but this came as no surprise, as it had already happened in other studies where participation was not obligatory (Cain and Policastri, 2011).

With regard to weaknesses, those students who do not want to compromise their privacy because of Facebook do not like making friends with teachers either; and many of them think that Facebook is only a tool to have fun and that it must be kept apart from teaching. In general, if they do not use Facebook, it is not for technological reasons or due to lack of skills. It was clearly observed that more negative attitudes towards Facebook appeared among those students who had not used it in the subject. It remains to be determined whether they did not use Facebook because they had these preconceived negative ideas or whether, conversely, their negative opinions were due to the fact that they do not use it. It also became clear that Business students gave a lower score to negative aspects in Facebook and actually use it to a greater extent. It would be interesting to check if the type of degree chosen by these Business students -more oriented towards the trade and business world- where Facebook and other social networks are so often being used and have proved so profitable, generates a more positive vision of this tool.

\section{REFERENCES}

Cain, J. and Policastri, A. (2011). "Instructional design and assessment. Using Facebook as an informal learning environment". American Journal of Pharmaceutical Education. 75 (10). Article 207.

Dogoriti, E.; Pange, J. and Anderson, G.S. (2014). "The use of social networking and learning management systems in English language teaching in higher education". CampusWide Information Systems. 31(4), pp. 254-263. 
Duncan, D.G. and Barczyk, C.C. (2013). "Facebook in the University Classroom: Do Students Perceive that it Enhances Community of Practice and Sense of Community?" International Journal of Business and Social Science. 4(3), pp. 1-14.

Duvall, M.V. and Kirwin, J.L. (2012). "Using Facebook to Facilitate Course-Related Discussion Between Students and Faculty Members". American Journal of Pharmaceutical Education. 76(2), pp. 1-5.

Fortune, M.F.; Spielman, M. and Pangelinan, D.T. (2011). "Students' Perceptions of Online or Face-to-Face Learning and Social Media in Hospitality". Journal of Online Learning and Teaching. 7(1), pp. 1-16.

Gneiser, M.; Heidemann, J.; Klier, M.; Landherr, A. and Probst, F. (2012). "Valuation of Online Social Networks Taking into account Users' Interconnectedness". Information Systems and E-Business Management. 10(1), pp. 61-84.

Halawati, A.J.S. and Soh, R. (2013). The integration of authentic learning principles and facebook in service learning. The Turkish Online Journal of Educational Technology. 12(4), pp. 192- 199.

Harris, Ch. W. (2012), "The uses of Facebook technologies in Hospitality curriculum on an experiential learning platform for a new generation of students". Asia Pacific Journal of Marketing and Logistics. 24(5), pp. 805-825.

Lamb, A. and Johnson, L. (2013). "A decade of Facebook. Can we still be Friends?". Teacher Librarian. 41(2), pp. 58-63.

Lampe, C.; Wohn, D.Y.; Vitak, J.; Ellison, N.B. and Wash, R. (2011). "Student use of Facebook for organizing collaborative classroom activities". Computer-Supported Collaborative Learning. 6(3), pp. 329-347.

Li, L. and Pitts, J. P. (2009). "Does it really matter? Using virtual office hours to enhance student-faculty interaction". Journal of Information Systems Education. 20(2), pp. 175-185.

Llorens-Cerdà, F. and Capdeferro-Planas, N. (2011). "Facebook's Potential for Collaborative e-Learning". Revista de Universidad y Sociedad del Conocimiento (RUSC). 8(2), pp. 197-210.

Nielsen (2011). "State of the Media: The Social media Report". Internet document. http://cn.nielsen.com/documents/Nielsen-Social-Media-Report_FINAL_090911.pdf

Mahmud, M.M. and Ching, W.S. (2012). "Facebook does it really work for L2 learners". Academic Research International. 3(2), pp. 357-370.

Mills, N. (2011). "Situated learning through social networking communities: The development of joint enterprise, mutual engagement, and a shared repertoire". CALICO Journal. 28(2), 345-368.

Omar, H.; Embi, M.A. and Yunus, M.M. (2012). "ESL Learners' Interaction in an Online Discussion via Facebook". Asian Social Science. 8(11), pp. 67-74.

Ramirez, A.; Hine, M.J.; Ji, S.; Ulbrich, F. and Riordan, R. (2009). "Learning to succeed in a flat world: information and communication technologies for a new generation of business students". Learning Inquiry. 3(3), pp. 157-175.

Shattry, Ch.; Henriksen, D.; Wu, M.L. and Dickson, W.P. (2013). "Situated Learning with Online Portafolios. Classroom websites and Facebook". TechTrends. 57(3), pp. 2025.

Siegle, D. (2011). "Facing Facebook: A Guide for Nonteens". Gifted Child Today. 34(2), pp. 14-19. 
Suki, N.M. (2013) "Students' dependence on smart phones: The influence of social needs, social influences and convenience". Campus-Wide Information Systems. 30(2), pp.124-134.

Suwannatthachote, P. and Tantrarungroj, P. (2012). "How Facebook Connects Students" Group Work Collaboration: A Relationship between Personal Facebook Usage and Group Engagement". Creative Education. 3, pp 15-19.

Taylor, S.A.; Mulligan, J.R. and Ishida, Ch. (2012). "Facebook, Social Networking, And Business Education". American Journal of Business Education. 5(4), pp. 437-447.

The Cocktail Analysis (2013). "Quinta Oleada Observatorio de Redes Sociales". Internet Document. http://www.slideshare.net/TCAnalysis/5-oleada-observatorio-redessociales.

Wang, J. (2013). "What higher educational professionals need to know about today's students: Online social networks". TOJET: The Turkish Online Journal of Educational Technology. 12(3), pp. 180-193. 


\section{ANNEX}

Survey Questiontaire: "Use of the Facebook Social Network in Human Resource Management"

Circle your answer.

1. I am registered on the Facebook group called Human Resource Management

YES

No

Circle your assessment about the following questions, 1 meaning $=I$ totally disagree; and 5 meaning $=1$ totally agree. If you don't know what to answer, circle $N$

2. I don't want to make friends with teachers on Facebook

$12345 \mathrm{~N}$

3. I don't want to make friends with classmates on Facebook.

$12345 \mathrm{~N}$

4. I don't want my photographs or my private information to be available to others

$12345 \mathrm{~N}$

5. Facebook shouldn't be used for any subject; its use must be social, for fun.

$12345 \mathrm{~N}$

6. I can't manage on Facebook.

$12345 \mathrm{~N}$

7. I don't want to learn to use Facebook

8. I fear that using Facebook in a subject may mean wasting my time

$12345 \mathrm{~N}$

9. Facebook has many distractions (games, advertisements...) hard to avoid for me

$12345 \mathrm{~N}$

If you answered NO to the first question, you have already finished; otherwise, please continue.

10. I have used Facebook in this subject to interact with classmates or teachers

$12345 \mathrm{~N}$

11. The subject's Facebook group has allowed me to see and share information whenever and wherever I wanted.

12. I am a passive member of the subject's Facebook group (I look at it and nothing else)

$12345 \mathrm{~N}$

13. I have used the subject's Facebook group to say "Like" to some publications and comments.

$12345 \mathrm{~N}$

14. I have used the subject's Facebook group to make comments on the subject.

$12345 \mathrm{~N}$

15. I have used the subject's Facebook group to upload contents (videos, links....)

$12345 \mathrm{~N}$

16. My interest in the subject has increased after using Facebook.

$12345 \mathrm{~N}$

17. The use of Facebook in the subject has improved its work environment

$12345 \mathrm{~N}$

18. The use of Facebook in the subject has improved my relationships with classmates

I $2345 \mathrm{~N}$

19. The use of Facebook in the subject has improved my relationship with the teacher(s)

20. The information shared by means of Facebook in this subject is very valuable for my training.

21. It would be very useful to incorporate social networks (such as Facebook) into other subjects of this degree

22. I am satisfied with the use of the Facebook social network in this subject.... 
Table 1: Study technical specifications

\begin{tabular}{|l|r|}
\hline Population & 191 University Students enrolled on Human Resource Management subject \\
Sample Size & 125 valid responses $(65.4 \%)$ \\
Sampling Error & $5.26 \%$ \\
Survey Date & May 2014 \\
\hline
\end{tabular}

Table 2: Measures for constructs and Reliability

\begin{tabular}{|c|c|c|c|}
\hline Construct & Source & Measure & $\begin{array}{c}\text { Reliability' } \\
\text { (Cronbach's } \alpha)\end{array}$ \\
\hline Weaknesses & $\begin{array}{c}\text { Literature } \\
\text { review }\end{array}$ & $\begin{array}{c}8 \text { items, 1-to-5 } \\
\text { likert scale }\end{array}$ & $\begin{array}{c}0.687 \\
\text { acceptable }\end{array}$ \\
\hline Strengths & $\begin{array}{c}\text { Literature } \\
\text { Review }\end{array}$ & $\begin{array}{c}13 \text { items, 1-to-5 } \\
\text { likert scale }\end{array}$ & 0.854 good \\
\hline
\end{tabular}

Table 3: Students registered on the Facebook group by degree

\begin{tabular}{|c|c|c|c|c|c|}
\hline & & & \multicolumn{2}{|c|}{ Registered on Facebook } & \\
\hline Degree & Enrolled & Answer & No & Yes & Sig. \\
\hline Business & 57 & $35(61.4 \%)$ & $2(5.7 \%)$ & $33(94.3 \%)$ & 10.705 \\
\hline$\overline{\mathrm{HR}}$ & 134 & $90(67.1 \%)$ & $31(34.4 \%)$ & $59(65.6 \%)$ & $(0.001)$ \\
\hline
\end{tabular}

Table 4: Weaknesses, difference of means by registration and by degree

\begin{tabular}{|l|l|l|c|}
\hline & Registered & Mean & Statistic (Sign.) \\
\hline I don't want friendship with & Yes & 1.57 & $4475.5(0.000)^{* *}$ \\
classmates & No & 2.13 & \\
\hline I don't want to use Facebook in & Yes & 2.10 & $-3.932(0.000)^{*}$ \\
subjects, but I do want to use it for fun & No & 3.13 & \\
\hline I don't want to learn to use Facebook & Yes & 1.40 & $947.5(0.002)^{* *}$ \\
& No & 2.23 & \\
\hline & Degree & & \\
\hline I don't want friendship with teachers & Business & 2.36 & $-2.229(0.028)^{*}$ \\
& HR & 2.95 & \\
\hline I don't want to use Facebook in & Business & 1.68 & $1847.0(0.001)^{* *}$ \\
\hline slibjects, but I do want to use it for fun & HR & 2.62 & \\
\hline
\end{tabular}

*t statistic, equality of means test

***Mann-Whitney's U statistic

http://mc.manuscriptcentral.com/cwis 
Table 5: Weaknesses, difference of means for variables by registration on Facebook and by degree

\begin{tabular}{|l|l|l|c|}
\hline & Registered & Mean & Statistic (Sign.) \\
\hline Privacy & Yes & 2.4792 & $-2.980(0.003)^{*}$ \\
& No & 2.9435 & \\
\hline Technological & Yes & 1.5054 & $964.5(0.002)^{* *}$ \\
Deficit & No & 2.1935 & \\
\hline & Degree & & \\
\hline Privacy & Business & 2.3235 & $-2.463(0.015)^{*}$ \\
& HR & 2.7004 & \\
\hline Technological & Business & 1.3529 & $1865.0(0.024)^{* *}$ \\
Deficit & HR & 1.8034 & \\
\hline
\end{tabular}

*t statistic, equality of means test

**Mann-Whitney's U statistic

http://mc.manuscriptcentral.com/cwis 
Figure 1: Weaknesses of Facebook in Teaching

http://mc.manuscriptcentral.com/cwis 